\title{
Volatile corrosion inhibitors for ferrous and non-ferrous metals and alloys: A review
}

\author{
F.A. Ansari, ${ }^{1}$ C. Verma, ${ }^{2,3}$ Y.S. Siddiqui, ${ }^{4}$ E.E. Ebenso ${ }^{2,3}$ \\ and M.A. Quraishi ${ }^{*}$
}

${ }^{1}$ Department of Applied Chemistry, JETGI, Faculty of Engineering, Barabanki, India-225203

${ }^{2}$ Department of Chemistry, School of Mathematical \& Physical Sciences, Faculty of Agriculture, Science and Technology, North-West University (Mafikeng Campus), Private Bag X2046, Mmabatho 2735, South Africa

${ }^{3}$ Material Science Innovation \& Modelling (MaSIM) Research Focus Area, Faculty of Agriculture, Science and Technology, North-West University (Mafikeng Campus),

Private Bag X2046, Mmabatho 2735, South Africa

${ }^{4}$ Assistant Professor, Department of Civil Engineering, JETGI, Faculty of Engineering, Barabanki, India-225203

${ }^{5}$ Center of Research Excellence in Corrosion, Research Institute, King Fahd University

of Petroleum and Minerals, Dhahran 31261, Saudi Arabia

*E-mail: mumtaz.quraishi@kfupm.edu.sa,maquraishi.apc@itbhu.ac.in

\begin{abstract}
Volatile corrosion inhibitors (VCIs) or vapor phase inhibitors (VPIs) represent a class of compounds that are employed to protect the corrosion or oxidation of ferrous and nonferrous metals and alloys where other surface treatments are impractical. The VCIs release slowly inside the sealed airspace and actively adsorb and prevent corrosion. Several VCIs have been employed as effective inhibitors for several metals like iron, zinc, aluminum, etc. and their alloys. Literature study revealed that VCIs protect metallic corrosion either by forming a surface protective film on the metal surface or neutralizing the corrosive surrounding reagents $\mathrm{H}_{2} \mathrm{O}, \mathrm{SO}_{2}, \mathrm{H}_{2} \mathrm{~S}$ and $\mathrm{CO}_{2}$, etc. Because of the high volatility, VCIs easily vaporize and their vapors condense on the metallic surface as well as the volume available in the crevices, pores and cracks thereby gives complete protection where they used. The VCIs can be inserted into coatings, foams, adhesives, powders, sprays and plastics. Several VCIs are known those act as effective inhibitors by themselves and few other VCIs are also known those hydrolyzed products act as corrosion inhibitors. The inhibition ability as well as quantity of the adsorbed VCIs on metallic surfaces can be determined by several commonly employed techniques such as contact angle, radiotracer, polarographic and electrocapilarity methods. Present review article describes the assortment of previous works published on VCIs as corrosion inhibitors for ferrous and
\end{abstract}


non-ferrous metals and alloys. The present report also deals with salient features of VCIs and mechanism of their action.

Keywords: VCIs, vapour pressure, corrosion inhibition, vapour phase inhibitors, DICHAN, mechanism of VCIs action.

Received: February 7, 2018. Published: March 14, 2018

doi: $\underline{10.17675 / 2305-6894-2018-7-2-2}$

\section{Introduction}

\subsection{Economic Importance}

Corrosion is a worldwide problem to be addressed by educational and industrial divisions because it unfavorably affecting the economy of developed as well as developing countries [1-3]. According to NACE study conducted in 2002, the United States losses around US \$ 276 billion in 1998 because of the damage caused by corrosion. The cost of corrosion further increased to around US \$ 2.2 trillion in the year 2011 [3, 4]. Recently, the damage due to corrosion (worldwide) exceeds greater than US \$ 2.5 trillion that results into loss of about $3.4 \%$ of world GDP. Similar to the most of the countries, GDP of India and South Africa are also being greatly affected due to corrosion as it has been estimated that economic damage of India and South Africa due to corrosion are Rs. 5,000,000 (US \$ 100 billion) and R130 billion (US \$ 9.6 billion), respectively. Nowadays, several methods of corrosion anticipation are being employed that can reduce the damage caused by corrosion from US \$ 375 billion (15\%) to US \$ 875 billion (35\%) [4]. The damage of corrosion is most pronounced during industrial cleaning processes such as acid descaling and acid pickling of metallic ores to remove the corrosion products collected on the metallic surfaces [5-7]. During these cleaning processes a huge amount of metallic contents are lost because of corrosive nature of the cleaning media (acidic solutions) and therefore during these processes use of corrosion inhibitors is extremely anticipated $[8,9]$. Organic compounds are most frequently utilized inhibitors among the several accessible methods of corrosion prevention such as like coating and painting, anodic and cathodic protections, alloying and de-alloying etc. The criteria behind their commercial uses are based on their easily availability, highly effectiveness and ease of application in addition to their economic synthesis using commercially available raw starting chemicals [10-14]. Generally, these compounds strongly interact through their $\pi$ - and non-bonding electrons with metallic surface and form protective surface film via coordination bonds. This inhibitor film acts as barrier between surrounding environment and metal surface thereby helps in corrosion protection [15-17]. The presence of functional groups $\left(-\mathrm{NH}_{2},-\mathrm{OCH}_{3}\right.$, $-\mathrm{OH},-\mathrm{NO}_{2},-\mathrm{COOH},-\mathrm{CONH}_{2}$, etc. $)$, homo-atomic $(>\mathrm{C}=\mathrm{C}<,-\mathrm{C} \equiv \mathrm{C}-)$ and heteroatomic $(>\mathrm{C}=\mathrm{O},>\mathrm{C}=\mathrm{S},-\mathrm{C}=\mathrm{N}-,-\mathrm{N}=\mathrm{O},-\mathrm{C} \equiv \mathrm{N}$, etc. ) multiple bond of carbocyclic and heterocyclic rings facilitate the adsorption of organic inhibitors on metal surfaces [18-20]. Generally, in strongly acidic media most of the organic inhibitors exist in their cationic (positive) form as their heteroatoms easily undergo protonation, while in the same 
environment metallic surface exist in the negative forms due to adsorption of anionic counter ions (e.g. $\mathrm{Cl}^{-}, \mathrm{SO}_{4}^{2-}, \mathrm{NO}_{3}^{-}$) on the surface [21, 22]. Therefore, during the first stage of adsorption in acidic solutions, metal surface and inhibitor molecules interact by electrostatic force of attractions i.e. physisorption process. However, during the later stage of adsorption, these inhibitors interact via their non-bonding and $\pi$-electrons and form coordination bonds i.e. chemisorption [23].

\subsection{Factors affecting corrosion}

Corrosion is an inherent property of pure metals except silver, gold and platinum, and its rate largely depends upon the nature of surrounding environments [21-23]. Obviously, an increase in the surrounding temperature results into corresponding increase in corrosion rate [21-23]. Although, presence of organic inhibitors in corrosive acidic environment decreases corrosion rate, however nature of groups exerted most significant role on the inhibition effect of these inhibitors. The electron releasing groups such as amino $\left(-\mathrm{NH}_{2}\right)$, hydroxyl $(-\mathrm{OH})$ and methoxy $\left(-\mathrm{OCH}_{3}\right)$ substituents increase the inhibition performance of the organic inhibitors as they increase the electron density at the active sites that favors metal-inhibitor interactions [24, 25]. In contrast, electron withdrawing groups like carboxyl $(-\mathrm{COOH})$, cyano $(-\mathrm{CN})$, ester $\left(-\mathrm{COOC}_{2} \mathrm{H}_{5}\right)$, nitro $\left(-\mathrm{NO}_{2}\right)$ substituents decrease inhibition performance because they withdraw the electron density from the active sites that disprove the metal-inhibitor interactions [24, 25]. The electron donating and/or withdrawing nature of groups can be measured by their Hammett constant $(\sigma)$ values. The negative value of Hammett constant (e.g. $\sigma=-0.17$ for $\left.p-\mathrm{CH}_{3}\right)$ suggests that substituent under consideration is electron releasing in nature and can favor the adsorption of organic inhibitor in which it is present. Conversely, a group with positive Hammett constant value (e.g. $\sigma=0.78$ for $p-\mathrm{NO}_{2}$ ) indicates that concern substituent group is electron withdrawing in nature and disfavors the adsorption of organic inhibitor molecules. It has been demonstrated that addition of alkyl substituents in organic inhibitors/ compounds enhances their hydrophobic character that results into their limited solubility in the polar solvents like water, $\mathrm{HCl}$ and $\mathrm{NaOH}$ etc. [26, 27]. It is obvious that for proper metal-inhibitor interactions, the inhibitor molecules should be properly dissolved and homogenized. The geometry of the inhibitor molecule on metallic surfaces largely influences their inhibition property because an inhibitor with flat or horizontal geometry on metal surface would shelter larger area as compared to the same inhibitor with vertical or non-planar geometry [24,25]. Sometimes, presence of bulky alkyl substituents causes steric repulsion/hindrance which in turn affects the geometry of inhibitor molecules on the metallic surfaces [26,27]. In that case non-substituted inhibitor showed relatively better corrosion inhibition as compared to their alkyl or other substituted groups. Beside the nature of group, concentration of the organic inhibitors play very significant role towards the metallic corrosion inhibitors in the aggressive media. The inhibition performance of organic inhibitors increases successively on 
increasing their concentration till the maximum value is not attained. The concentration at which organic compounds show their maximum inhibition efficiency are called as optimum concentration. It has been postulated that below optimum concentration, inhibitor molecules adsorb on the metallic surfaces by their flat orientations and therefore surface coverage successively increases on increasing inhibitor concentration. However, at or above optimum concentration where maximum surface coverage occurs further increase in concentration causes increases in intermolecular force of repulsion among the inhibitor molecules i.e. below optimum concentration intermolecular force of attraction among metal surface and inhibitor molecules dominates over intermolecular force of repulsion among them and just reverse occur above optimum concentration.

Presence of humidity in the surrounding environment along with organic, inorganic salts as impurities enhances the probability and rate of corrosion because polar (water) and ionic species increase the ionic conductivity of the corrosive medium [28-30]. Movement of the corrosive medium also plays a potential role of the corrosiveness of the aggressive solution. In the flowing case, metallic corrosion would be more severe because moving electrolyte molecules continuously remove the rusts and scales accumulated on the surface leading to exposure of new metallic surface for corrosion as compared to the static conditions. Under static conditions, the nature of corrosion products can be estimated by Pilling-Bedworth ratio which is presented by $M d / n m D[31,32]$. In this formula, $m$ and $M$ represent atomic mass and molecular mass of metal under consideration and corrosion products (rusts), respectively, $d$ and $D$ denote the densities of metal under taken and corrosion products, respectively and $n$ signifies number of metallic atom in the formula of corrosion product. For instance, in corrosion products $\mathrm{Al}_{2} \mathrm{O}_{3}, \mathrm{Fe}_{2} \mathrm{O}_{3}$, and $\mathrm{Fe}_{3} \mathrm{O}_{4} n$ is equal to 2, 2 and 3, respectively [32]. In the situation $M d / n m D<1$, it is assumed that surface volume of the corrosion products is smaller than the volume of metallic surface and therefore surface film have some pores, cracks and some exposed area and would be nonprotective in nature. However, for situation $M d / n m D>1$ it can be assumed that volume of the corrosion products is greater than the volume of metallic surface therefore surface film in this situation will uniformly cover metallic surface and will be protective in nature.

\subsection{Methods of corrosion protection}

Corrosion is an extremely destructive problem adversely affecting the economics of most of the developing and developed countries therefore its prevention is highly anticipated primarily during industrial acid cleaning and oil well acidification processes [24, 25]. Several methods of corrosion prevention have been developed depending upon the nature of metallic species and surrounding environments [24,25]. The methods of corrosion protection can be broadly divided into three categories namely anodic protection, cathodic protection and mixed type of protection, depending upon the mode of action of the inhibitors. Anodic inhibitors also known as passivating inhibitors those inhibit corrosion by retarding the anodic oxidation reaction through a process known as passivation. In the passivation process these inhibitors retard metal corrosion by adsorption and formation of 
surface oxide layer (passive) that results into large anodic displacement in the corrosion potential $\left(E_{\text {corr }}\right)$ [33]. Several anodic inhibitors have been reported as chromate, nitrite and nitrate those can form passive oxide layer on metallic surface in non-oxygenic environments [33]. These passivating species are known as oxidizing anions. On the other hands, there are few other passivating inhibitors such as phosphate, molybdate and tungstate are known those can form passive layer in the presence of oxygenic environment only [33]. Cathodic inhibitors are chemical compounds those decrease the cathodic corrosion reaction or precipitates on the cathodic sites. The precipitation of the cathodic inhibitors results into sudden increase in the surface impedance because precipitated cathodic inhibitors reduce the rate of diffusion of chemical species responsible for corrosion. Based on their mode of action, cathodic inhibitors may be cathodic precipitates, cathodic poison and oxygen scavenger types [33]. It is well demonstrated that hydrazine and sodium sulfite consume the surrounding oxygen molecules by chemically reacting with them and thereby slow down the cathodic reaction. These two compounds act as oxygen scavengers [33, 34]. Presence of antimony and arsenic retards the combination of hydrogen ions $\left(\mathrm{H}^{+}\right)$during the cathodic hydrogen evolution reaction. The two metallic species act as cathodic poisons. Lastly, sodium, magnesium and zinc precipitate in their oxide forms on the cathodic area and thereby act as cathodic precipitates [33]. The organic compounds, inorganic metals and their oxides and mixtures of the inorganic-organic compounds have been employed in the several common corrosive media for almost every kinds of metals and alloys [35]. Alloying and dealloying of the metallic species can improve their corrosion resistance behavior. The use of organic compounds as inhibitors has gained the highest priority because these compounds are relatively economic, effective and can be derived from commercially available starting chemicals. Their high inhibition efficiency is based on the fact that they contain several adsorption centers in the form of polar functional groups and multiple bonds $[9,35]$.

\subsection{Corrosion inhibitors}

Till today several types of inhibitors have been developed and used for effective inhibition of metallic corrosion those can be divided into several classes or groups depending upon their nature. Recently, use of plant extracts in the field of corrosion inhibition is among the widely growing methods because of their green and sustainable nature [36-38]. The phytochemicals present in the extracts offer strong metal-inhibitor interactions that come in form of high inhibition efficiencies of these extracts. Moreover, these phytochemicals are naturally synthesized using atmospheric carbon dioxide $\left(\mathrm{CO}_{2}\right)$ and water in the presence of sunlight without using any toxic chemicals or solvents that offers them as one of the greenest chemicals to be used for various applications including the field of corrosion inhibition [3638]. Each plant extracts generally contain several phytochemicals those can effectively adsorb on the metallic surface and inhibit their corrosion. Chemical medicines or drugs are other commonly employed green inhibitors for metallic corrosion in various electrolytic media [39-41]. Their biological and natural origin offer them a green and environmental friendly chemicals to be used for several purposes. Generally, drugs are chemically complex 
molecules those possess several active sites in the form of heteroatoms and extensive conjugation [39-41]. The extensive use of inorganic compounds as inhibitors as such or in combination with organic compounds for solution phase as well as for coating has been reported in literature. The presence of inorganic compounds in the solution enhances the effectiveness of the organic inhibitors through the phenomenon of synergism [42]. Literature survey shows that synthetic compounds have been employed most commonly but their recent application now based on their several physiochemical properties like cost, lifespan, effectiveness, ease of synthesis and applications, solubility in the test medium, temperature and $\mathrm{pH}$ dependent stability etc. Most of the used synthetic inhibitors are toxic and hazardous for living organisms and also to the surrounding environments because of their multistep synthesis and use of conversional energy source for heating those are associated with huge discharge of environmental malignant chemicals into the surrounding and reduced yield owing to their association with several workups and purification processes. In view of this recently organic inhibitors are being synthesized using the one step multicomponent reactions (MCRs) which is generally connected with ease to handle and high reaction yield. The reduction in the number of purification and workup steps because of their one step nature, MCRs are also associated with high atom economy (high yield). The conventional heating methods for activation of reactive molecules is an outdated protocol that offers very slow heating of the reaction vessels and require several hours or even days for completion of the reactions. The microwave and ultrasound irradiations are being frequently utilized as energy (heating) source for various chemical transformations like esterification, hydrolysis, condensation, cyclization, nitration, alkylation, acylation etc. because of their quick and uniform heating throughout the reaction vessels. In summary, it can be say that ultrasound and microwave in combination of MCRs is one of the best methods for the development of the green synthetic inhibitors particularly solvent free condition or in green solvents like water and ionic liquids.

\subsection{An introduction to volatile corrosion inhibitors (VCIs)}

\subsubsection{Historical background}

Volatile corrosion inhibitors (VCIs) are also known as vapour phase corrosion inhibitors (VPCIs). The efficiency of VCIs depends on its adsorption ability on the metal's surface, the strength of this adsorption, and the temperature dependence of its vapor pressure. However, the corrosion inhibition of numerous components of US military equipments by dicyclohexylammonium nitrite (DICHAN) in 1940s is being considered as first work on VCIs [43]. The majority of strong aliphatic and alicyclic base compounds were effective vapor-phase inhibitors. It was found that compounds like cyclohexylamine, hexamethyleneimine, piperidine, morpholirne [44], and benzylamine were found as effective VCI's for ferrous metals.

Ammonia and lower amines were used extensively for protection of metallic materials in power industry during the 20 s to 30 s decades of $20^{\text {th }}$ century [43-45]. Many formulations 
were suggested which may protect ferrous as well as nonferrous metals i.e. benzimidazole, 2-benzimidazolethiol, and 2-mercaptobenzotriazole were reported to be effective for $\mathrm{Cu}, \mathrm{Al}$, $\mathrm{Zn}$ and their alloys. Thereafter, several VCIs have been developed and employed for inhibition of ferrous and non-ferrous metallic corrosion in their vapour phase.

\subsubsection{Vapor pressure $\left(p^{0}\right)$ and its measurement}

The VCI molecules have strong tendency to scape in surrounding air because of their high volatility nature thereby these molecules can adsorb on the metal surface (passivation) and avoids the contact of corrosive surrounding [43-46]. The volatility or sublimation which can be expressed in the term of saturated vapour pressure $\left(p^{0}\right)$ is one of the most characteristics properties of the VCIs. Literature survey reveals that compounds with values of saturated vapour pressure $\left(p^{0}\right)$ greater than in the range of $10^{-2}-10^{-7} \mathrm{mmHg}$ can be used as VCIs $[43,45]$. There are several VCIs that have ability to protect the metallic surface either by themselves or their hydrolysis products have been reported in literature. For instance, nitrite-hexamethylenetetramine and nitrile-carbamide become effective as vapour phase inhibitors for metallic corrosion because of the formation of highly volatile ammonium nitrite through hydrolysis reaction $[43,45]$.

$$
\begin{gathered}
\left(\mathrm{CH}_{2}\right)_{6} \mathrm{~N}_{4}+4 \mathrm{H}_{2} \mathrm{O}+10 \mathrm{NaNO}_{2}=4 \mathrm{NH}_{4} \mathrm{NO}_{2}+6 \mathrm{CH}_{2} \mathrm{O}+4 \mathrm{NaOH} \\
\mathrm{CO}\left(\mathrm{NH}_{2}\right)_{2}+2 \mathrm{H}_{2} \mathrm{O}+2 \mathrm{NaNO}_{2}=\mathrm{Na}_{2} \mathrm{CO}_{3}+2 \mathrm{NH}_{4} \mathrm{NO}_{2}
\end{gathered}
$$

Generally, vaporization of most of the VCIs in gas phase occurs without their decomposition however, carbon dioxide and cyclohexylamine vaporization occurs mainly with either thermal or hydrolytic dissociation $[43,45,46]$. A substantial attention has been paid to describe the mechanism of vaporization/ sublimation with the particular emphasis of amines and DICHAN which obviously depends upon interaction with the surrounding environment $[43,45,46]$. Presence of moisture or humidity favors adsorption of VCI molecules on metallic surface because of increased volatility (saturation vapour pressure; $p^{0}$ ) of their components through hydrolysis. However, the decrease in $p^{0}$ with increase in humidity have been observed have also been reported in few cases. Besides, humidity temperature is another important factor that limits the volatility of the VCIs. Several methods have been developed for measurement of $p^{0}$ those can be classified into static, evaporation from open surface, dynamic, boiling point measurement and their modified forms.

(i) Regnault dynamic method involves the heating of weighted amount of inhibitor at the constant temperature under the flowing stream of oxygen free nitrogen followed by measurement of weight loss. The vaporization rate of the VCI molecule at several studied temperatures can be computed using following equation [43, 46, 47]:

$$
\frac{\text { Total volume of compound }}{\text { Volume of vapor }}=\frac{\text { Total pressure }}{\text { Vapor pressure }}
$$

The value of vapor pressure can be obtained by plotting a graph between vapour pressure and temperature. 
(ii) Knudsen effusion method employs the measurement of the rate of gas effusion through a small orifice. The value of vapour pressure can be determined using following formula $[46,47]$ :

$$
p_{t}^{0}=\frac{\Delta W}{K S t} \cdot\left(\frac{T}{M}\right)^{\frac{1}{2}}
$$

In the equation $4, \Delta W$ represents the weight loss of compound, $K$ is a constant, $S$ is the area of orifice, $t$ is the time, $T$ is the absolute temperature and $M$ is the molecular weight of the tested compound.

(iii) Torsion effusion method employed the measurement of recoil force established when VCI molecules in gas form effuse from pores into a vacuum. When a compound is kept in an effusion vessel suspended from a fiber and its vapour escapes in a horizontal route from two strangely (eccentrically) placed pores, the fibber will be twisted through some angles. The magnitude of the vapour pressure can be computed from the angle of deflection using following relationship [46, 47]:

$$
p_{t}^{0}=\frac{2 K B}{f_{1} d_{1} a_{1}+f_{2} d_{2} a_{2}}
$$

In the above equation, $p^{0}$ represents the vapour pressure, $B$ is the steady angle of torque produced by effusion at a constant temperature $(T), d_{1}$ and $d_{2}$ represent the distance between pore 1 and pore 2 from the axis of origin, $f_{1}$ and $f_{2}$ represent the correction factors and $a_{1}$ and $a_{2}$ are the area of the cavities. The $K, f, a$ and $d$ factors are difficult to measure with adequate precision and therefore another modified equation has been proposed by calibrating the measuring instrument with a compound with known vapour pressure at several temperatures. In that case Equation 5 can be simplified as $[46,47]$ :

$$
P_{\mathrm{t}}=K_{\mathrm{t}} B
$$

In the equation (6), $K_{\mathrm{t}}$ is constant and its calculated value can be employed to determine the vapour pressure of other compounds under the same temperature range.

(iv) Boiling point determination method employs determination of boiling temperature and/or pressure of the undertaken compounds when their $p^{0}$ equal to external pressure $(P)$.

(v) Microbalance method involves the measurement of the weight loss using microwave of the high accuracy at measured temperature after calibration with compounds of the recognized vapour pressure.

A relationship between the physicochemical and electronic characteristics of various metals and molecular parameters of inhibitors predicts performance and inhibition efficiency of volatile corrosion inhibitor (VCI's) of ferrous and nonferrous metals [48-52]. It was predicted that the unambiguous prediction of the inhibitive effects of compounds and estimation of the adsorptivity of compounds on metals and, consequently, their inhibitive properties from the general electronic characteristics of the compound and the 
metal (ionization potential and electron work function) does not allow to a general approach. The estimation of the inhibitive effect was based on the correlation between the first adiabatic potentials of compounds and "resonance" potentials of metals and metal oxides. It can be only used to predict possible forms of adsorption bonds between a compound and a metal.

\subsubsection{Effect of temperature on vapour pressure}

Obviously, molecular structure and molecular weight (mass) exert significant effect on the $p^{0}$ value (volatility) of the VCI molecules. It was demonstrated that increase in the molecular mass generally decreased the volatility of the organic compound. However, it is recall that composition and mechanism of the evaporation depends upon the external factors along with the inherent properties of the VCI molecules. Among the external factors, temperature exerts the most significant effect of the vapour pressure of the VCI molecules. The effect of temperature can be best explained by Claussius-Clapeyron equation $[46,47,53]$ :

$$
\log (P)=\mathrm{A}-B / T
$$

where, $p$ is the usual vapour pressure, $A$ and $B$ are constants and $T$ is the absolute temperature. The value of latent heat of sublimation can be calculated using equation (7). The calculated values of vapour pressure $\left(p^{0}\right)$ and talent heat of sublimation of the some selected compounds are listed in Table 1. The inspection of results shown in Table it can be observed that values of $p^{0}$ are decreasing on increasing the value of talent heat for nitrobenzoates and for amine benzoates. The decrease in the $p^{0}$ values of these compounds on increasing their latent heat is attributed to the corresponding increase in the intermolecular force of attraction and the increase in the molecular weight that in turn enhances the Van der Waals force of attraction. Variation of vapour pressure $\left(p^{0}\right)$ with latent heat of sublimation for DICHAN, cyclohexylamine benzoate and di-isopropylamine nitrile are presented in Figure 1 [46, 47, 53].

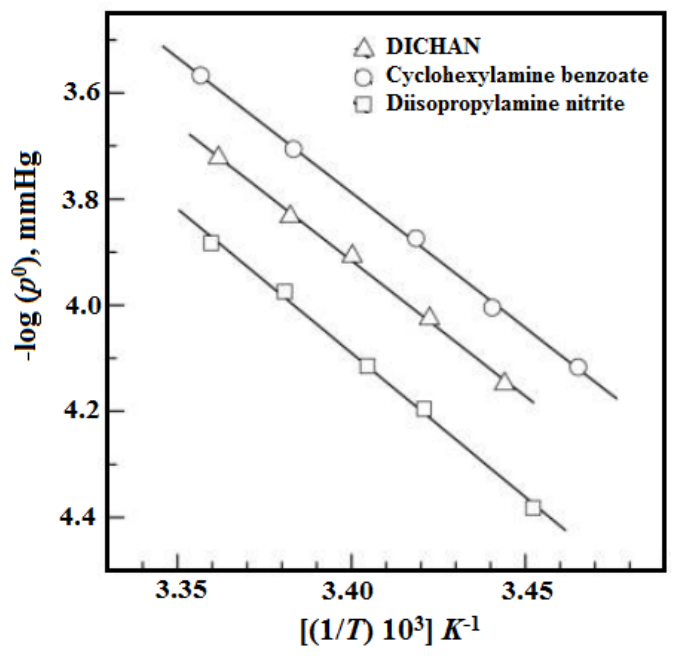

Figure 1. Change in the vapour pressure with latent heat of sublimation of DICHAN, cyclohexylamine benzoate and di-isopropylamine nitrile. 
Table 1.

\begin{tabular}{|c|c|c|c|}
\hline Test Material & Inhibitor & Test Environment & Ref. \\
\hline $\begin{array}{l}\text { Mild steel, } \\
\text { copper, and } \\
\text { brass }\end{array}$ & 6-Amino-benzothiazole & $100 \%$ humidity & {$[78]$} \\
\hline Brass & $\beta$-Amino alcohols & $100 \%$ humidity & [79] \\
\hline \multirow{2}{*}{ Mild steel } & Bis-piperidiniummethyl-urea & Humid atmosphere & {$[80]$} \\
\hline & $\begin{array}{l}\text { Bis-piperidiniummethyl-urea (BPMU) and } \\
\text { mono-piperidiniummethyl-urea(MPMU) }\end{array}$ & Humid atmosphere & {$[65]$} \\
\hline $\begin{array}{l}\text { Mild steel, } \\
\text { copper, and } \\
\text { brass }\end{array}$ & Benzoic hydrazide stearate (BHS) & $\begin{array}{l}\text { Aggressive environments } \\
\text { of } \mathrm{SO}_{2} \text { and } \mathrm{NaCl} \text { at high } \\
\text { relative humidity and } \\
\text { high temperature. }\end{array}$ & [81] \\
\hline $\begin{array}{l}\text { Mild steel, } \\
\text { copper, brass, }\end{array}$ & $\begin{array}{l}\text { Laurichydrazide (LH) with cinnamic acid } \\
\text { (LHC), succinic acid (LHS), }\end{array}$ & \multirow{2}{*}{$100 \% \mathrm{RH}$} & \multirow[t]{2}{*}{ [82] } \\
\hline $\begin{array}{l}\text { zinc, and } \\
\text { aluminum }\end{array}$ & $\begin{array}{l}\text { Nitrobenzoic acid (LHNB), Phthalic acid } \\
\text { (LHP), and maleic acid (LHM) }\end{array}$ & & \\
\hline $\begin{array}{l}\text { Aluminium, } \\
\text { mild steel, } \\
\text { brass, and } \\
\text { copper }\end{array}$ & $\begin{array}{l}\text { 1-(2-Aminoethyl)-2-dec-9-enyl-2- } \\
\text { imidazoline salicylic acid, nitrobenzoic } \\
\text { acid, phthalic acid, and cinnamic acid }\end{array}$ & & [83] \\
\hline Mild steel & $\begin{array}{l}\text { Piperazine and its derivatives such as } \\
\text { phosphates, carbonates, benzoates, } \\
\text { cinnamate and maleate }\end{array}$ & $\begin{array}{l}100 \% \text { relative humidity } \\
\text { at } 40^{\circ} \mathrm{C} \text { for } 8 \text { hours and } \\
\text { then for } 16 \text { hours under } \\
\text { the room temperature }\end{array}$ & {$[84]$} \\
\hline Brass & $\begin{array}{l}\text { 1,3-bis-diethylamino-propan-2-ol as VPI } \\
\text { for steel component }\end{array}$ & $100 \% \mathrm{RH}$ & {$[85]$} \\
\hline $\begin{array}{c}\text { Steel } \\
\text { component }\end{array}$ & Diethylamine phosphate & $100 \% \mathrm{RH}$ & {$[86]$} \\
\hline \multirow[t]{3}{*}{ Carbon steel } & $\begin{array}{l}\text { Thiomorpholin-4-methyl-phosphonic acid } \\
\text { and morpholin-4-methyl-phosphonic acid }\end{array}$ & & \multirow[t]{2}{*}{ [87] } \\
\hline & Morpholine and its derivatives & & \\
\hline & Amine carboxylate & & [88] \\
\hline Mild steel & $\begin{array}{c}\text { Dicyclohexylaminebenzotriazole (DCHA- } \\
\text { BTZ) } \\
\text { octylpalmamide (OTP) } \\
\text { octylcaprilamide (OTC) } \\
\text { octylstearamide (OTS) }\end{array}$ & $\mathrm{Cl}_{2}$ environment & [89] \\
\hline
\end{tabular}




\begin{tabular}{|c|c|c|c|}
\hline Test Material & Inhibitor & Test Environment & Ref. \\
\hline & $\begin{array}{c}\text { Oleic hydrazide benzoate (OHB)oleic } \\
\text { hydrazide salicylate (OHS) }\end{array}$ & $\mathrm{NaCl}$ environment & {$[90]$} \\
\hline & Dicyclohexylamine & $\mathrm{CO}_{2}$ Environment & [91] \\
\hline & Urea-amine & High humidity & {$[92]$} \\
\hline & Dicyclohexylamine nitrite & & [93] \\
\hline & Atmospheric amines & & {$[74]$} \\
\hline & Wood bark oil & $\mathrm{HCl}$ Environment & [94] \\
\hline & Thyme & $\mathrm{H}_{2} \mathrm{~S}$ gas environment & {$[95]$} \\
\hline \multirow{2}{*}{ Mild steel } & Rape-cake extract & & {$[96]$} \\
\hline & Menthol & $\mathrm{NaCl} \& \mathrm{HCl}$ & {$[53,97]$} \\
\hline $\begin{array}{l}\text { Copper and } \\
\text { electronic items }\end{array}$ & DICHAN (dicyclohexylammonium nitrite) & $\begin{array}{l}\text { High humidity, } \\
\text { Hydrogen chloride and } \\
\text { sulphide contaminated } \\
\text { environment }\end{array}$ & [98] \\
\hline \multirow{4}{*}{ Mild steel } & $\begin{array}{l}\text { Triethylamine (TEA), Ethylamine (EA) } \\
\text { and N-Ethylaniline (NEA) }\end{array}$ & & {$[50]$} \\
\hline & $\begin{array}{c}n \text {-Caprylic acid (CA), } n \text {-Butyric acid (BA), } \\
N, N \text {-dimethyl propylene urea (DMPU) and } \\
\text { 2-Amino Benzothiazole } \\
(\mathrm{ABT})\end{array}$ & temperature of $40.0^{\circ} \mathrm{C}$ & {$[99]$} \\
\hline & $\begin{array}{l}\text { Diallylamine (DAA), 1-Benzylimidazole } \\
\text { (1-BIZ) and 5-Aminotetrazole (5-ATZ) }\end{array}$ & temperature of $50.0^{\circ} \mathrm{C}$ & {$[54]$} \\
\hline & Thiocarbohydrazides and their salts & $\begin{array}{l}\text { Vapour Phase } \\
\text { environment }\end{array}$ & {$[100]$} \\
\hline
\end{tabular}

Altsybeeva et al. $[54,55]$ studied the action mechanism of volatile inhibitors having different vapour pressure but did not get any regular trend. Further, it was also discussed about the kinetics of VCIs from the surface of various metals, action mechanism and higher inhibition efficiency upon electrostatic application.

\subsubsection{Mechanism of VCIs action and Effect of $\mathrm{pH}$}

The inhibition of metallic corrosion by VCI molecules involves the two steps, first step comprises the vaporization of the VCI molecules into surrounding atmosphere and second step involves dissolution of vapour molecules into pre-adsorbed moisture film that provides adequate corrosion protection. The tendency of the VCI molecules to enhance the hydrophobic character of the moisture film on the metallic surface is one of the greatest interest in the field of corrosion inhibition using this technique $[48,56]$. Dissolution of the 
VCI molecules takes place when the $\mathrm{pH}$ of the moisture is not very high (basic) or very low (acidic). It has been reported that salts of weak volatile bases and acids can be best suited as VCIs. Most of the VCI molecules show their best activity in the pH range of 5.5 to $8.5[48,49]$. The VCI molecules can protect the metallic corrosion either by forming the protective film over the metal surface that isolates and relief from corrosion or neutralizing the corrosive agents present in the environment such as $\mathrm{H}_{2} \mathrm{O}, \mathrm{S}_{2} \mathrm{O}, \mathrm{CO}_{2}, \mathrm{SO}_{2}$ etc. Literature survey suggests that several methods such as contact angle, radiotracer and polarographic methods to measure electro-capillarity curves have been employed to determine the ability and quantity of the inhibitors adsorbed on the metallic surface. Figure 2 represents the mechanism of corrosion protection by VCIs.

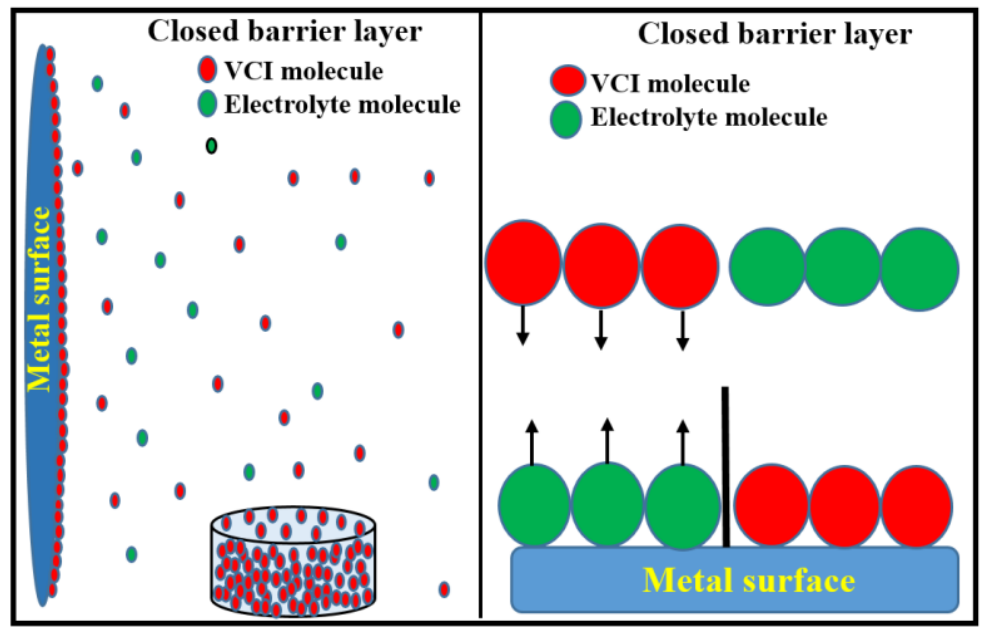

Figure 2. Mechanism of corrosion inhibition by VCI molecules.

\subsubsection{Advantages and disadvantages of VCIs}

The VCI molecules have ability of vaporize and condense on the metallic surfaces in order to make them less prone to corrosion. The VCIs have several advantages: (i) they can be inserted into adhesives, coatings, foams, powders, plastics and spray, (ii) they can be employed into packaging to retard the corrosion of stored items, (iii) they easily vaporize and their vapour moves quickly to cover the metallic surface and empty volume available for them until the saturation is established i.e. VCIs start their work once they are exposed to the environment, (iv) generally they fill all the surfaces including crevices, pores and cracks where ordinary inhibitors cannot penetrate, (v) VCIs form very thin inhibitive film that can be easily removed without affecting the properties of metallic surfaces and (vi) they can be used as corrosion protectors during the transport of metals and components. The VCI molecules can be used in several sectors such as in the military, nuclear and petrochemical plants, automotive industries, cultural heritage conservators, surgical equipments, electronic components manufacturers and producers of high precision electronic materials because of their high tendency to adsorb on the metallic surface. 
However, at the same time there are a few limitations of the VCIs such as sometime they increase the corrosion rate of non-ferrous metals and alloys.

\subsubsection{Methods of testing VPIs}

1.5.6.1. Vapor pressure determination. At some temperatures and pressures, a solid or liquid is in equilibrium with its vapor. This equilibrium pressure is called the vapor pressure of the solid or liquid. Standard Knudsen methods were used to determine the vapor pressure of various vapor phase corrosion inhibitors (VPCIs). The volatilization rate of VPI's is in the similar functional dependence upon temperature, so that more inhibitive material is evaporated at higher temperatures. Criterion for the selection of a compound to be used as a VPI is that it should not have very low or very high vapor pressure as to give lasting protection [57-59].

$$
P=\frac{W}{A t}\left[\frac{2 \pi R T}{M}\right]^{\frac{1}{2}}
$$

Where, $P=$ vapor pressure of the VPCI $(\mathrm{mmHg}), A=$ area of the orifice $\left(\mathrm{m}^{2}\right), t=$ time of exposure (sec.), $W=$ weight loss of substance $(\mathrm{kg}), T=$ temperature $(\mathrm{K}), M=$ molecular mass of the inhibitor $(\mathrm{kg})$ and $R=$ gas constant $\left(8.314 \mathrm{~J} \mathrm{~K}^{-1} \mathrm{~mol}^{-1}\right)$.

1.5.6.2. Weight loss test. All testing specimen were mechanically polished successively with the help of emery papers grading 100, 200, 300, 400 and $600 \mu$ and then thoroughly cleaned with plenty of triple distilled water, ethanol and acetone. Specimen were dried with hot air blower and stored in desiccators over silica gel. After recording initial weights of specimen on analytical balance, they were kept in different isolated chambers of air thermostat having fixed amount of VPCI at a constant temperature of $50^{\circ} \mathrm{C}$ for 24 hours of exposure time. A uniform thin film of VPCI was adsorbed onto the metal coupons after 24 hours of exposure. Then these coupons were transferred to a digitally controlled humidity chamber maintained at $85 \%$ humidity at a constant temperature of $50^{\circ} \mathrm{C}$ for 10 days [60]. The gravimetric evaluation cell is presented in Figure 3.

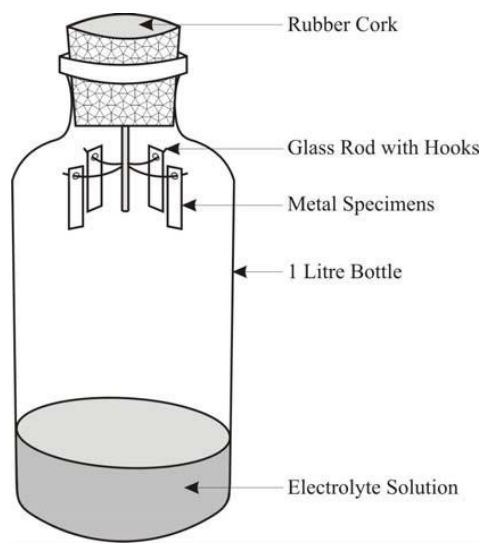

Figure 3. Gravimetric evaluation cell. 
1.5.6.3. Esckhe test. Eschke test was carried out on the pre weighed mechanically polished specimens. Kraft papers of suitable size were dipped in the VPCI for 30 seconds and then dried to adsorb uniform layer of the inhibitor on the Kraft papers. Then metal coupons were wrapped in VPCI impregnated Kraft papers and then taken in the humidity chamber maintained at $85 \%$ relative humidity maintained at a constant temperature of $50^{\circ} \mathrm{C}$ for first 12 hours and $50^{\circ} \mathrm{C}$ for next 12 hours, alternately for 10 days. This temperature cycle was maintained in two sets because of formation and condensation of the vapours of VPCI on mild steel surface regularly. After exposing the coupons for 10 days, the coupons were treated in same manner as treated in weight loss test to remove corrosion products and then corrosion rate (CR) and inhibition efficiency (IE) was calculated [61].

1.5.6.4. Salt Spray Method. After exposing the pre weighed mild steel coupons to VPCI in air thermostat for 24 hours, they were transferred to salt spray chamber having $3.0 \%$ sodium chloride solution maintained at constant temperature of $50^{\circ} \mathrm{C}$ for duration of 10 days along with blank specimens. After exposing the coupons for 10 days in $\mathrm{NaCl}$ spray, coupons were treated in same manner as treated in weight loss test to remove corrosion products and corrosion rate CR and inhibition efficiency (IE) was evaluated.

1.5.6.5. Sulfur Dioxide Test. $\mathrm{SO}_{2}$ test was carried out on the mild steel coupons of same dimension as in weight loss test. $\mathrm{SO}_{2}$ gas was prepared by dissolving $0.04 \mathrm{~g}$ of sodium thiosulphate in $30 \mathrm{~mL}$ aqueous solution of $1.0 \% \mathrm{NH}_{4} \mathrm{Cl}$ and $1.0 \% \mathrm{Na}_{2} \mathrm{SO}_{4}$ solution and $0.5 \mathrm{~mL}$ of $1.0 \mathrm{~N} \mathrm{H}_{2} \mathrm{SO}_{4}$ was added to the flask. Initially pre weighed and mechanically polished mild steel coupons were placed in air thermostat maintained at a constant temperature of $50^{\circ} \mathrm{C}$ for duration of 10 days. Definite weight of VPCIs in a petri dish and the flask, which is the source of $\mathrm{SO}_{2}$, were placed in the isolated chambers of air thermostat containing mild steel coupons. The specimens exposed for 10 days were then treated in same manner as treated in weight loss test to remove corrosion products and there $\mathrm{C}_{\mathrm{R}}$ and IE was calculated [57].

1.5.6.6. Metallurgical Research Microscopy Technique. To investigate the corrosion inhibition efficiency of VPCIs, micrographs of the corroded coupons treated with investigated VPCI were subjected to porosity study and morphology of surface. Percentage porosity (PP) and total objects (TO) shows the roughness of surface. On the other hand maximum perimeter and maximum area object ratio $(\mathrm{A} / \mathrm{O})$ provide the information about the size and depth of the pores on the surface of mild steel. A/O ratio is not very high as compared to that of salt spray test.

1.5.6.7. Potentiodynamic polarization measurements. The polarization measurements were determined by thin layer technique for different metals using the atmospheric corrosion monitor cell. The potential vary from cathodic to anodic direction from the corrosion potential and then the polarization measurements were carried out. The plot of $E v s$. $\log I_{\text {corr }}$ was made from which corrosion potential $\left(E_{\text {corr }}\right)$, corrosion current density $\left(I_{\text {corr }}\right)$, 
anodic and cathodic Tafel slopes $\left(\beta_{\mathrm{a}} \& \beta_{\mathrm{c}}\right)$ values are calculated. The inhibition efficiency for these systems is calculated using the following equation

$$
I E \%=\frac{I_{\text {corr }}^{0}-I_{\text {corr }}^{i}}{I_{\text {corr }}^{0}}
$$

where, $I_{\mathrm{corr}}^{0}$ and $I_{\mathrm{corr}}^{i}$ are the corrosion current density with and without inhibitor.

1.5.6.8. Electrochemical Impedance Spectroscopy. The method of impedance spectroscopy is a powerful tool for investigation of electrical properties of materials and interfaces of conducting electrodes. Relevant fields of application are the kinetics of charges in bulk or interfacial regions, the charge transfer of ionic or mixed ionic-ionic conductors, semiconducting electrodes, the corrosion inhibition of electrode processes, investigation of coatings on metals, characterization of materials and solid electrolyte as well as solid-state devices $[62,63]$.The VCl's doesn't amend the mechanism of dissolution of metal. Hence, it's purely depends on the charge transfer process. All experimental plots approximately have a semi-circular shape. The impedance measurement shows that the inhibition of the VCIs is characterized by increasing diameter of the arc which is acting the resistance.

The studies reveal that with the increase in inhibitor concentration there is an increase in charge transfer resistance $\left(R_{\mathrm{ct}}\right)$ value is ascertained to the formation of protective film on the metal/solution interface. The charge transfer process mainly controls the corrosion process. On the contrary, value of double layer capacitance $\left(C_{\mathrm{dl}}\right)$ decreases with increases in the inhibitor concentration. The $C_{\mathrm{dl}}$ is an electrical capacitor between the charged metal surface and the solution. This decrease in local dielectric constant and/or an increase in the thickness of the double layer causes decrease in $C_{\mathrm{d}}$, hence it is suggested that inhibitor molecules inhibit the iron corrosion by adsorption at the metal/acid interface

$$
C_{\mathrm{dl}}=\frac{1}{2 \pi f_{\max } R_{\mathrm{ct}}}
$$

where $C_{\mathrm{dl}}$ - double layer capacitance, $R_{\mathrm{ct}}$ - charge transfer resistance, $f_{\max }$ - frequency.

$$
I E \%=\frac{R_{\mathrm{ct}}^{0}-R_{\mathrm{ct}}^{i}}{R_{\mathrm{ct}}^{0}}
$$

\section{VCIs as corrosion inhibitors: literature survey}

\subsection{VCI as corrosion inhibitors for ferrous materials}

Steel in the form of carbon and mild steel being used is a main construction material in different industries because of its high mechanical strength and cost effective characteristics. The temporary corrosion protection of these materials is essential when they are transported from one place to other and during their storage. The role of VCIs to protect metals from atmospheric corrosion are among the most efficient and cost-effective 
method. The physicochemical aspects of VCI protective action are covered in a number of reviews [64]

Literature study suggests that several methods of protection have been developed and being incorporated for temporary protection of mild steel and carbon steel among them use of VCIs is the most effective, profitable and popular method. The selection of VCIs as corrosion inhibitors is primarily determined by their vapour pressure and nature of metallic surface to be protected. Zhang et al. $[65,66]$ demonstrated the inhibition effect of two VCIs namely, mono-piperidiniummethyl-urea (MPMU) and bis-piperidiniummethyl-urea (BPMU) for mild steel and carbon steel corrosion. Weight loss method was employed to measure the volatility of BPMU and MPMU. Electrochemical techniques were also employed to study the inhibition characteristic of these tested VCIs. Adsorption of both VCIs, BPMU and MPMU on mild steel surface was supported by X-ray photoelectron spectroscopy (XPS) method. Results showed that BPMU forms coordinate bonds with Fe atoms using its two nitrogen atoms, while MPMU coordinates with Fe atoms using its one nitrogen atom. The electrochemical results were supported by semi-empirical DFT approach which showed that energy band gap $(\Delta E)$ is minimum in the case of BPMU which results in its high inhibition efficiency as compared to the MPMU. Two tertiary amines namely, 1,3-bis-diethylamino-propan-2-ol (DEAP) and 1,3-di-morpholin-4ylpropan-2-ol (DMP) were synthesized, characterized and evaluated as VCIs for carbon steel employing chemical and electrochemical methods [67]. Results showed that DEAP showed best inhibition efficiency of $95 \%$ at $2.5 \times 10^{-2} \mathrm{M}$ concentration. The adsorption of both the VCIs followed Langmuir adsorption isotherm. Adsorption of DMP and DEAP molecules on carbon steel surface is supported by FT-IR method. Inhibition performance of both the VCIs enhanced on enhancing their concentrations as observed by potentiodynamic polarization study. The corrosion inhibition of mild steel by a few amines, azoles and carboxylates alone and their mixtures in acidic and basic media have been studied by electrochemical (OCP and EIS) methods [68]. Results showed that all studied compounds and their mixtures inhibit mild steel corrosion by passivating the metallic surface and the extent of passivation mainly depends upon nature of $\mathrm{pH}$. Kannan and coworkers [69] demonstrated inhibition property of several VCIs namely, octylsteramide (OTS), octylpalmamide (OTP), octylbenzamide (OTB) octylcaprylamide (OTC) and Dicyclohexylaminebenzotriazole (DCHAB) on mild steel corrosion in $\mathrm{H}_{2} \mathrm{~S}$ medium. Inhibition efficiency of the tested VCI molecules have been evaluated using weight, electrochemical and surface measurement methods. Results showed that adsorption of the VCI molecules obeyed the Langmuir adsorption isotherm. The adsorption of VCIs on metallic surface and surface morphologies of the inhibited and uninhibited metallic specimens were studied by SEM-EDX methods. The inhibition effect of these inhibitors has also been tested on mild steel in $\mathrm{Cl}_{2}$ gas environment using chemical, electrochemical and surface study methods and it was observed that OTS showed the best inhibition efficiency out of tested VCIs [70]. Thyme Extract of Thymus vulgar L. has also been tested as effective VCI for mild steel in sodium chloride solution using weight and polarization 
methods [71]. Inhibition of the extract increases with concentration and its adsorption on mild steel surface obeyed the Temkin adsorption isotherm. Results showed the volatile plant extract showed maximum efficiency of $84.9 \%$ at $1000 \mathrm{ppm}$ concentration. Estevao and Nascimento demonstrated the influence of zeolite and diatomaceous earths (DE) on the volatility rate and inhibition performance of the dicyclohexylammonium nitrobenzoate (DICHANB) and phosphate (DICHAP) for 1006 carbon steel corrosion [72]. Results showed that inhibition properties of both DICHANB and DICHAP did not enhanced by diatomaceous earths (DE), however presence of the zeolite significantly enhances the inhibition performance of tested VCIs. By considering the high inhibition efficiency of the sodium nitrite, the inhibition property of the dicyclohexylammonium nitrite for packaged steel materials was studied [73]. A variety of the experiments have been carried out and it was observed that dicyclohexylammonium nitrite undergoes vaporization and condensation on the metallic surface and therefore acts as efficient inhibitor.

The trend and technology has allowed new methods for a range of VCI applications to be reliably extended into new areas of applications. The corrosion protection in oil \& gas, military, automotive, electronic, electrical, and other industrial sectors see existing and new technologies which increase efficiency and service life and decrease the total cost [74-76].

\subsection{VCI as corrosion inhibitors for non-ferrous materials}

Use of vapor-phase corrosion inhibitors is one of the most effective methods for preventing atmospheric corrosion during transport and storage. In an attempt to develop multimetal vapor-phase corrosion inhibitors, five amino-benzothiazole derivatives were synthesized to investigate their inhibiting action on corrosion of mild steel, copper, and brass at $100 \%$ relative humidity by weight loss and potentiodynamic polarization methods. 6-Methoxyaminobenzothiazole cinnamate exhibited the best performance among all the studied compounds by giving $>90 \%$ inhibition efficiency for all the metals investigated. All the inhibitors shifted corrosion potential of all metals significantly to the noble direction, indicating that they are predominantly anodic inhibitors [77]. Some common VCIs that have been tested as corrosion inhibitors for ferrous and non-ferrous metals and alloys are presented in Table 1.

\section{Conclusions}

Present review paper describes the collection of the works that have been published on the corrosion inhibition performance of volatile corrosion inhibitors for ferrous and nonferrous metals and alloys. Obviously, the salts of weak and volatile acids and bases those have vapour pressure in between $10^{-2}$ to $10^{-7} \mathrm{mmHg}$ act as effective VCIs for metals and alloys. Various VCI molecules have been tested as effective inhibitors for ferrous and nonferrous metals and alloys. The VCI molecules inhibit metallic corrosion either by forming a surface protective film on the metal surface or neutralizing the corrosive surrounding reagents $\mathrm{H}_{2} \mathrm{O}, \mathrm{SO}_{2}, \mathrm{H}_{2} \mathrm{~S}$ and $\mathrm{CO}_{2}$ etc. The mechanism of corrosion inhibition by VCI molecules has also been described. Because of the high volatility, VCIs easily vaporize and 
their vapors condense on the metallic surface as well as the volume available in the crevices, pores and cracks thereby gives complete protection where they used. They can also be used in coatings, foams, adhesives, powders, sprays and plastics. The VCI molecules can act as inhibitors either as such or their hydrolyzed products can also be act as VCI molecules. The inhibition ability as well as quantity of the adsorbed VCIs on metallic surfaces can be determined by several commonly employed techniques such as contact angle, radiotracer, polarographic and electro-capillarity methods.

\section{References}

1. B. Wu, J.-L. Cao and L. Kang, "Influence of local corrosion on behavior of steel Ibeams subjected to end patch loading: Experiments", J. Constr. Steel Res., 2017, 135, $150-161$.

2. C. Verma, E.E. Ebenso and M. Quraishi, "Ionic liquids as green and sustainable corrosion inhibitors for metals and alloys: An overview", J. Mol. Liq., 2017, 233, $403-$ 414.

3. R.K. Gupta, M. Malviya, C. Verma and M. Quraishi, "Aminoazobenzene and diaminoazobenzene functionalized graphene oxides as novel class of corrosion inhibitors for mild steel: Experimental and DFT studies", Mater. Chem. Phys., 2017, 198, 360-373.

4. R.K. Gupta, M. Malviya, C. Verma, N.K. Gupta and M. Quraishi, "Pyridine-based functionalized graphene oxides as a new class of corrosion inhibitors for mild steel: an experimental and DFT approach", RSC Adv., 2017, 7, 39063-39074.

5. E. Naveen, B.V. Ramnath, C. Elanchezhian and S.M. Nazirudeen, "Influence of organic corrosion inhibitors on pickling corrosion behaviour of sinter-forged C45 steel and 2\% Cu alloyed C45 steel", J. Alloys Compd., 2017, 695, 3299-3309.

6. P. Dohare, K. Ansari, M. Quraishi and I. Obot, "Pyranpyrazole derivatives as novel corrosion inhibitors for mild steel useful for industrial pickling process: experimental and quantum chemical study", J. Ind. Eng. Chem., 2017, 52, 197-210.

7. S.H. Zaferani, M. Sharifi, D. Zaarei and M.R. Shishesaz, "Application of eco-friendly products as corrosion inhibitors for metals in acid pickling processes - A review", J. Environ. Chem. Eng., 2013, 1, 652-657.

8. A. Kumari, M.K. Jha, J.-C. Lee and R.P. Singh, "Clean process for recovery of metals and recycling of acid from the leach liquor of PCBs", J. Cleaner Prod., 2016, 112, $4826-4834$.

9. N.K. Gupta, C. Verma, M. Quraishi and A. Mukherjee, "Schiff's bases derived from Llysine and aromatic aldehydes as green corrosion inhibitors for mild steel: Experimental and theoretical studies", J. Mol. Liq., 2016, 215, 47-57.

10. S. Mo, H.Q. Luo and N.B. Li, "Study on the influences of two thiazole flavor ingredients on $\mathrm{Cu}$ corrosion caused by chloride ion", J. Colloid Interface Sci., 2017, 505, 929-939. 
11. L. Guo, S. Kaya, I.B. Obot, X. Zheng and Y. Qiang, "Toward understanding the anticorrosive mechanism of some thiourea derivatives for carbon steel corrosion: A combined DFT and molecular dynamics investigation", J. Colloid Interface Sci., 2017, 506, 478-485.

12. I. Obot, D. Macdonald and Z. Gasem, "Density functional theory (DFT) as a powerful tool for designing new organic corrosion inhibitors. Part 1: an overview", Corros. Sci., 2015, 99, 1-30.

13. D. Winkler, M. Breedon, P. White, A. Hughes, E. Sapper and I. Cole, "Using high throughput experimental data and in silico models to discover alternatives to toxic chromate corrosion inhibitors", Corros. Sci., 2016, 106, 229-235.

14. F. Liu, L. Zhang, X. Yan, X. Lu, Y. Gao and C. Zhao, "Effect of diesel on corrosion inhibitors and application of bio-enzyme corrosion inhibitors in the laboratory cooling water system”, Corros. Sci., 2015, 93, 293-300.

15. J. Haque, V. Srivastava, C. Verma and M. Quraishi, "Experimental and quantum chemical analysis of 2-amino-3-((4-((S)-2-amino-2-carboxyethyl)-1H-imidazol-2-yl) thio) propionic acid as new and green corrosion inhibitor for mild steel in $1 \mathrm{M}$ hydrochloric acid solution," J. Mol. Liq., 2017, 225, 848-855.

16. A. Fateh, M. Aliofkhazraei and A. Rezvanian, "Review of corrosive environments for copper and its corrosion inhibitors", Arab. J. Chem., 2017, in press. doi: https://doi.org/10.1016/j.arabjc.2017.05.021

17. C. Verma, L. Olasunkanmi, I. Obot, E.E. Ebenso and M. Quraishi, "5-Arylpyrimido[4,5-b]quinoline-diones as new and sustainable corrosion inhibitors for mild steel in $1 \mathrm{M} \mathrm{HCl}$ : a combined experimental and theoretical approach", $R S C A d v$., 2016, 6, $15639-15654$.

18. N. Anusuya, J. Saranya, P. Sounthari, A. Zarrouk and S. Chitra, "Corrosion inhibition and adsorption behaviour of some bis-pyrimidine derivatives on mild steel in acidic medium", J. Mol. Liq., 2017, 225, 406-417.

19. C. Verma, L.O. Olasunkanmi, E.E. Ebenso, M. Quraishi and I. Obot, "Adsorption behavior of glucosamine-based, pyrimidine-fused heterocycles as green corrosion inhibitors for mild steel: experimental and theoretical studies", J. Phys. Chem. C, 2016, 120, 11598-11611.

20. C.B. Verma, M. Quraishi and A. Singh, "2-Aminobenzene-1,3-dicarbonitriles as green corrosion inhibitor for mild steel in $1 \mathrm{M} \mathrm{HCl}$ : Electrochemical, thermodynamic, surface and quantum chemical investigation", J. Taiwan Inst. Chem. Eng., 2015, 49, 229-239.

21. R. Kumar, R. Chopra and G. Singh, "Electrochemical, morphological and theoretical insights of a new environmentally benign organic inhibitor for mild steel corrosion in acidic media", J. Mol. Liq., 2017, 241, 9-19.

22. C. Verma, M. Quraishi and A. Singh, "A thermodynamical, electrochemical, theoretical and surface investigation of diheteroaryl thioethers as effective corrosion inhibitors for mild steel in $1 \mathrm{M} \mathrm{HCl",} \mathrm{J.} \mathrm{Taiwan} \mathrm{Inst.} \mathrm{Chem.} \mathrm{Eng.,} \mathrm{2016,} \mathrm{58,} \mathrm{127-140.}$ 
23. A. Fouda, M. Ismail, G. EL-ewady and A. Abousalem, "Evaluation of 4-amidinophenyl-2,2'-bithiophene and its aza-analogue as novel corrosion inhibitors for CS in acidic media: experimental and theoretical study", J. Mol. Liq., 2017, 240, 372-388.

24. C. Verma, M. Quraishi, L. Olasunkanmi and E.E. Ebenso, "L-Proline-promoted synthesis of 2-amino-4-arylquinoline-3-carbonitriles as sustainable corrosion inhibitors for mild steel in $1 \mathrm{M} \mathrm{HCl}$ : experimental and computational studies", $R S C A d v$., 2015, 5, 85417-85430.

25. C. Verma, L.O. Olasunkanmi, I. Obot, E.E. Ebenso and M. Quraishi, "2,4-Diamino-5(phenylthio)-5H-chromeno-[2,3-b]pyridine-3-carbonitriles as green and effective corrosion inhibitors: gravimetric, electrochemical, surface morphology and theoretical studies", RSC Adv., 2016, 6, 53933-53948.

26. H.Z. Al-Sawaad, A.S. Al-Mubarak and A.M. Haddad, "The inhibition effects of dimethylol-5-methyl hydantoin and its derivatives on carbon steel alloy", J. Mater. Environ. Sci., 2010, 1, 227-238.

27. H.Z. Al-Sawaad, "Kinetic study for the hydroxymethylation of the rubeonic acid in alkaline medium and evaluation of Rubeonic and its derivatives as corrosion inhibitor for carbon steel by theoretical study", J. Mater. Environ. Sci., 2012, 3, 248-261.

28. Y. Yang, L. Guo, H. Liu, Factors affecting corrosion behavior of SS316L as bipolar plate material in PEMFC cathode environments, international journal of hydrogen energy, 37 2012, 13822-13828.

29. A. Bauer, T. Mehner, B. Awiszus, T. Lampke, Detection and Prediction of CorrosionAffecting Parameters in Cold Flat Rolling Processes, Procedia engineering, 184 2017, 22-29.

30. Y.-P. Song, L.-Y. Song, G.-F. Zhao, Factors affecting corrosion and approaches for improving durability of ocean reinforced concrete structures, Ocean Engineering, 31 (2004) 779-789.

31. B. Mazères, C. Desgranges, C. Toffolon-Masclet, D. Monceau, Experimental study and numerical simulation of high temperature $\left(1100-1250^{\circ} \mathrm{C}\right)$ oxidation of prior-oxidized zirconium alloy, Corros. Sci., 103 2016, 10-19.

32. X. Yu, B. Jiang, H. Yang, Q. Yang, X. Xia, F. Pan, High temperature oxidation behavior of Mg-Y-Sn, Mg-Y, Mg-Sn alloys and its effect on corrosion property, Appl. Surf. Sci., 353 2015, 1013-1022.

33. M. Finšgar, J. Jackson, Application of corrosion inhibitors for steels in acidic media for the oil and gas industry: a review, Corros. Sci., 86 2014, 17-41.

34. S.H. Zaferani, M.R. Shishesaz, Corrosion Inhibition of Carbon Steel in Acidic Solution by Alizarin Yellow GG “AYGG”, J Pet Environ Biotechnol, 5 2014, 2.

35. C. Verma, E.E. Ebenso, M. Quraishi, Corrosion inhibitors for ferrous and non-ferrous metals and alloys in ionic sodium chloride solutions: A review, J. Mol. Liq., 2017, 248, 927-942. 
36. P. Parthipan, J. Narenkumar, P. Elumalai, P.S. Preethi, A.U.R. Nanthini, A. Agrawal and A. Rajasekar, "Neem extract as a green inhibitor for microbiologically influenced corrosion of carbon steel API 5LX in a hypersaline environments", J. Mol. Liq., 2017, 240, 121-127.

37. A. Ehsani, M. Mahjani, M. Hosseini, R. Safari, R. Moshrefi and H.M. Shiri, "Evaluation of Thymus vulgaris plant extract as an eco-friendly corrosion inhibitor for stainless steel 304 in acidic solution by means of electrochemical impedance spectroscopy, electrochemical noise analysis and density functional theory", J. Colloid Interface Sci., 2017, 490, 444-451.

38. H.L.Y. Sin, A.A. Rahim, C.Y. Gan, B. Saad, M.I. Salleh and M. Umeda, "Aquilaria subintergra leaves extracts as sustainable mild steel corrosion inhibitors in $\mathrm{HCl}$ ", Measurement, 2017, 109, 334-345.

39. G. Gece, "Drugs: A review of promising novel corrosion inhibitors", Corros. Sci., 2011, 53, 3873-3898.

40. I. Rotaru, S. Varvara, L. Gaina and L.M. Muresan, "Antibacterial drugs as corrosion inhibitors for bronze surfaces in acidic solutions", Appl. Surf. Sci., 2014, 321, 188-196.

41. J.H. Al-Fahemi, M. Abdallah, E.A. Gad and B. Jahdaly, "Experimental and theoretical approach studies for melatonin drug as safely corrosion inhibitors for carbon steel using DFT", J. Mol. Liq., 2016, 222, 1157-1163.

42. R. Hudson and C. Warning, "Influence of halide mixtures with organiccompounds on dissolution of and hydrogen absorption by low-C steel in $\mathrm{H}_{2} \mathrm{SO}_{4}$ ", Corros. Sci., 1970, 10, 121-134.

43. D. Bastidas, E. Cano and E. Mora, "Volatile corrosion inhibitors: a review", AntiCorros. Meth. Mater., 2005, 52, 71-77.

44. N.N. Andreev and Yu.I. Kuznetsov, "Volatile Inhibitors of Metal Corrosion. I. Vaporization", Int. J. Corros. Scale Inhib., 2012, 1, 16-25. doi: 10.17675/2305-68942012-1-1-016-025

45. N.N. Andreev and Yu.I. Kuznetsov, "Physicochemical aspects of the action of volatile metal corrosion inhibitors", Russ. Chem. Rev., 2005, 74, 685-695.

46. Yu.I. Kuznetsov, "Current state of the theory of metal corrosion inhibition", Prot. Met., 2002, 38, 103-111.

47. I. Rosenfeld, B. Persiantseva and P. Terentiev, "Mechanism of metal protection by volatile inhibitors", Corrosion, 1964, 20, 222t-234t.

48. A.I. Altsybeeva, V.V. Burlov, N.S. Fedorova, T.M. Kuzinova and G.F. Palatik, "Volatile inhibitors of atmospheric corrosion of ferrous and nonferrous metals. I. Physical and chemical aspects of selection of starting reagents and synthetic routes", Int. J. Corros. Scale Inhib., 2012, 1, no. 1, 51-64. doi: 10.17675/2305-6894-2012-1-1051-064

49. A.I. Altsybeeva, V.V. Burlov, N.S. Fedorova, T.M. Kuzinova and G.F. Palatik, "Volatile inhibitors of atmospheric corrosion of ferrous and nonferrous metals. II. Prediction of the efficiency of volatile inhibitors of atmospheric corrosion of steel (with 
Schiff and Mannich bases as examples)", Int. J. Corros. Scale Inhib., 2012, 1, no. 1, 99-106. doi: 10.17675/2305-6894-2012-1-2-099-106

50. N.N. Andreev and Yu.I. Kuznetsov, "Volatile inhibitors of metal corrosion. II. Interaction of systems being protected with the environment and corrosion prevention conditions", Int. J. Corros. Scale Inhib., 2012, 1, no. 2, 146-153. doi: 10.17675/23056894-2012-1-2-146-153

51. A.I. Altsybeeva, V.V. Burlov, N.S. Fedorova and T.M. Kuzinova, "Volatile inhibitors of atmospheric corrosion of ferrous and nonferrous metals III. VNKh-L-408 inhibitor: basics of production and application technology", Int. J. Corros. Scale Inhib., 2013, 2, no. 1, 9-16. doi: $10.17675 / 2305-6894-2013-2-1-009-016$

52. N.N. Andreev and Yu.I. Kuznetsov, "Volatile inhibitors of atmospheric corrosion. III. Principles and methods of efficiency estimation", Int. J. Corros. Scale Inhib., 2013, 2, no. 1, 39-52. doi: 10.17675/2305-6894-2013-2-1-039-052

53. J. Bastidas, B. Chico, M. Alonso and E. Mora, "Corrosion of bronze by acetic and formic acid vapours, sulphur dioxide and sodium chloride particles", Mater. Corros., $1995, \mathbf{4 6}, 515-519$.

54. A.I. Altsybeeva, V.V. Burlov, N.S. Fedorova and T.M. Kuzinova, "Volatile inhibitors of atmospheric corrosion of ferrous and nonferrous metals. IV. Application of the VNKh-L-408 inhibitor in an electrostatic field", Int. J. Corros. Scale Inhib., 2013, 2, no. 3, 194-202. doi: 10.17675/2305-6894-2013-2-3-194-202

55. A.I. Altsybeeva, V.V. Burlov, N.S. Fedorova and S.M. Reshetnikov, "Volatile inhibitors of atmospheric corrosion of ferrous and nonferrous metals. V. Study of the adsorption of inhibitors on steel from an aqueous electrolyte solution", Int. J. Corros. Scale Inhib., 2013, 2, no. 4, 277-286. doi: 10.17675/2305-6894-2013-2-4-277-286

56. N.D. Tomashov, "Theory of corrosion and protection of metals", 1966, 672 pp., The Macmillan Company, New York.

57. V. Saini and H. Kumar, "Study of amine as vapour phase corrosion inhibitors for mild steel under different aggressive atmospheric conditions at high temperature", Int. J. Eng. Inn. Tech., 2014, 3, 248-256.

58. M.A. Quraishi and D. Jamal, "Synthesis and evaluation of some organic vapour phase corrosion inhibitors, Indian J. Chem. Tech., 2004, 11, 459-464.

59. S. Dogra, "Physical chemistry through problems", New Age International, 1984.

60. P. Premkumar, K. Kannan and M. Natesan, "Evaluation of menthol as vapor phase corrosion inhibitor for mild steel in $\mathrm{NaCl}$ environment”, Ara. J. Sci. Eng., 2009, 34, 71.

61. V. Saini and H. Kumar, "DAA, 1-BIZ and 5-ATZ as Vapour Phase Corrosion Inhibitors for Mild Steel under Different Aggressive Atmospheric Conditions at High Temperature", Int. Lett. Chem., Phys. Astron., 2014, 36, 174-192.

62. F. Mansfeld, "Use of electrochemical impedance spectroscopy for the study of corrosion protection by polymer coatings", J. Appl. Electrochem., 1995, 25, 187-202.

63. U. Retter and H. Lohse, Electrochemical impedance spectroscopy, Electroanalytical Methods, 2010, Springer, pp. 159-177. 
64. N.N. Andreev, O.A. Goncharova and S.S. Vesely, "Volatile inhibitors of atmospheric corrosion. IV. Evolution of vapor-phase protection in the light of patent literature", Int. J. Corros. Scale Inhib., 2013, 2, no. 3, 162-193. doi: 10.17675/2305-6894-2013-2-3$162-193$

65. D.-q. Zhang, Z.-x. An, Q.-y. Pan, L.-x. Gao and G.-d. Zhou, "Comparative study of bis-piperidiniummethyl-urea and mono-piperidiniummethyl-urea as volatile corrosion inhibitors for mild steel", Corros. Sci., 2006, 48, 1437-1448.

66. D.-q. Zhang, Z.-x. An, Q.-y. Pan, L.-x. Gao and G.-d. Zhou, "Volatile corrosion inhibitor film formation on carbon steel surface and its inhibition effect on the atmospheric corrosion of carbon steel", Appl. Surf. Sci., 2006, 253, 1343-1348.

67. G. Gao, C.H. Liang and H. Wang, "Synthesis of tertiary amines and their inhibitive performance on carbon steel corrosion", Corros. Sci., 2007, 49, 1833-1846.

68. U. Rammelt, S. Koehler and G. Reinhard, "Use of vapour phase corrosion inhibitors in packages for protecting mild steel against corrosion", Corros. Sci., 2009, 51, 921-925.

69. P. Kannan, P. Jithinraj and M. Natesan, "Multiphasic inhibition of mild steel corrosion in $\mathrm{H}_{2} \mathrm{~S}$ gas environment", Arab. J. Chem., 2018, 11, 388-404.

70. T.A. Söylev and M. Richardson, "Corrosion inhibitors for steel in concrete: State-ofthe-art report", Constr. Build. Mater., 2008, 22, 609-622.

71. P. Premkumar, K. Kannan and M. Natesan, "Thyme extract of Thymus vulgar L. as volatile corrosion inhibitor for mild steel in $\mathrm{NaCl}$ environment", Asian J. Chem., 2008, 20, 445 .

72. L. Estevao and R. Nascimento, "Modifications in the volatilization rate of volatile corrosion inhibitors by means of host-guest systems", Corros. Sci., 2001, 43, 11331153.

73. A. Wachter, T. Skei and N. Stillman, "Dicyclohexylammonium Nitrite, A Volatile Inhibitor for Corrosion Preventive Packaging", Corrosion, 1951, 7, 284-294.

74. A.I. Altsybeeva, V.V. Burlov, N.S. Fedorova and S.M. Reshetnikov, "Volatile inhibitors of atmospheric corrosion of ferrous and nonferrous metals. V. Study of the adsorption of inhibitors on steel from an aqueous electrolyte solution", Int. J. Corros. Scale Inhib., 2013, 2, no. 4, 277-286. doi: 10.17675/2305-6894-2013-2-4-277-286

75. S. Koehler and G. Reinhard, "VCI containing package material - mode of functioning", Int. J. Corros. Scale Inhib., 2014, 3, no. 4, 286-306. doi: 10.17675/2305-6894-2014-34-286-306

76. E. Lyublinski, P. Lynch, I. Roytman and T. Yakubovskaya, "Application experience and new approaches for volatile corrosion inhibitors", Int. J. Corros. Scale Inhib., 2015, 4, no. 2, 176-192. doi: 10.17675/2305-6894-2015-4-2-176-192

77. L.V. Ramanathan, Corrosão e seu controle, 1988 (in Portuguese).

78. J. Rawat and M. Quraishi, "Influence of some 6-methoxy-aminobenzothiazole derivatives on corrosion of ferrous and nonferrous metals under vapor-phase conditions", Corrosion, 2003, 59, 238-241. 
79. G. Gao and C. Liang, "Some $\beta$-amino alcohols compounds as green volatile corrosion inhibitors for brass", J. Electrochem. Soc., 2007, 154, C144-C151.

80. D.Q. Zhang, L.X. Gao and G.D. Zhou, "Polyamine compound as a volatile corrosion inhibitor for atmospheric corrosion of mild steel", Mater. Corros., 2007, 58, 594-598.

81. M. Quraishi and D. Jamal, "Inhibition of metals corrosion by a new vapour phase corrosion inhibitor", J. Metall. Mater. Sci., 2005, 47, 45-50.

82. M. Quraishi, V. Bhardwaj and J. Rawat, "Prevention of metallic corrosion by lauric hydrazide and its salts under vapor phase conditions", J. Am. Oil Chem. Soc., 2002, 79, 603-609.

83. M. Quraishi, D. Jamal and V. Bhardwaj, "Development and testing of new volatile corrosion inhibitors for multilmetal systems", Mater. Perform., 2003, 42, 44-48.

84. M. Quraishi, F. Ansari and J. Rawat, "Investigation of piperazine and its derivatives as vapor phase corrosion inhibitor for mild steel", Open Electrochem. J., 2009, 1, 32.

85. G. Gao and C.H. Liang, "1,3-Bis-diethylamino-propan-2-ol as volatile corrosion inhibitor for brass", Corros. Sci., 2007, 49, 3479-3493.

86. A. Subramania, A.S. Priya and T. Vasudevan, "Diethylamine phosphate as VPI for steel components", Mater. Chem. Phys., 2006, 100, 193-197.

87. H. Amar, T. Braisaz, D. Villemin and B. Moreau, "Thiomorpholin-4-ylmethylphosphonic acid and morpholin-4-methyl-phosphonic acid as corrosion inhibitors for carbon steel in natural seawater", Mater. Chem. Phys., 2008, 110, 1-6.

88. E. Vuorinen and W. Skinner, "Amine carboxylates as vapour phase corrosion inhibitors", Brit. Corros. J., 2002, 37, 159-160.

89. G. Sorell, "The role of chlorine in high temperature corrosion in waste-to-energy plants", Mater. High Temp., 1997, 14, 207-220.

90. Sudheer, M. Quraishi, E.E. Ebenso and M. Natesan, "Inhibition of Atmospheric Corrosion of Mild Steel by New Green Inhibitors under Vapour Phase Condition", Int. J. Electrochem. Sci., 2012, 7, 7463-7475.

91. D.-Q. Zhang, L.-X. Gao and G.-D. Zhou, "Self-assembled urea-amine compound as vapor phase corrosion inhibitor for mild steel", Surf. Coat. Technol., 2010, 204, 16461650 .

92. E. Cano, D. Bastidas, J. Simancas and J. Bastidas, "Dicyclohexylamine nitrite as volatile corrosion inhibitor for steel in polluted environments", Corrosion, 2005, 61, 473-479.

93. X. Ge, A.S. Wexler and S.L. Clegg, "Atmospheric amines - Part I. A review, Atmospheric Environment", 2011, 45, 524-546.

94. N. Poongothai, P. Rajendran, M. Natesan and N. Palaniswamy, "Wood bark oils as vapour phase corrosion inhibitors for metals in $\mathrm{NaCl}$ and $\mathrm{SO}_{2}$ environments", Indian J. Chem. Technol., 2005, 12, 641-647.

95. P. Premkumar, K. Kannan and M. Natesan, "Natural thyme volatile corrosion inhibitor for mild steel in $\mathrm{HCl}$ environment", J. Metall. Mater. Sci., 2008, 50, 227-234.

96. E. Chygyrynets and V. Vorobyova, "A study of rape-cake extract as eco-friendly vapor phase corrosion inhibitor", Chem. Chem. Technol., 2014, 8, 235-242. 
97. P. Premkumar, K. Kannan and M. Natesan, "Effect of menthol coated craft paper on corrosion of copper in $\mathrm{HCl}$ environment", Bull. Mater. Sci., 2010, 33, 307-311.

97. M.E. Tarvin and B.A. Miksic, "Volatile corrosion inhibitors for protection of electronics", Conference of National Association of Corrosion Engineers (NACE), 1989, Citeseer, 9 pp.

99. H. Kumar, V. Saini and V. Yadav, "Study of vapour phase corrosion inhibitors for mild steel under different atmospheric conditions", Int. J. Engg. \& Innovative Technol., 2013, 3, 206-211.

100. F. Ansari and M. Quraishi, "Prevention of metallic corrosion by thiocarbohydrazides and their salts in vapor phase environment", Chem. Eng. Commun., 2010, 198, 61-72. 